\title{
Constitutive Modeling of Hot Deformation of Carbon Steels in The Intercritical Zone
}

\author{
Juan Cancio Jiménez-Lugos*a, (1), José María Cabrera-Marrero ${ }^{b,}$ (), José Federico Chávez-Alcaläb, \\ José Manuel Hallen-López, Josué López-Rodríguez ${ }^{b}$ \\ ${ }^{A}$ Universidad Politécnica de Catalunya, Barcelona, España. \\ ${ }^{B}$ Instituto Politécnico Nacional - ESIQIE, Ciudad de Mexico, Mexico.
}

Received: June 10, 2021; Revised: January 02, 2022; Accepted: January 19, 2022

\begin{abstract}
A previous constitutive modeling for single-phase steels is extended using the mixing law to predict the behavior of hot deformation in the dual phase ferritic-austenitic intercritical zone of $\mathrm{Fe}-\mathrm{C}-\mathrm{Mn}-\mathrm{Si}$ alloys. Mixing law considers two phases instead one, so one phase formula was modified. The constant's values used represents average values to the same conditions in austenitic and ferritic model. The amount of each phase is determined as function of temperature and chemical composition. The developed constitutive modeling is validated by comparing the theoretical stress-strain curves with experimental isothermal uniaxial compression tests of 1008 and 1035 carbon steels at different temperatures and strain rates. The compression tests were carried out in a dilatometer with the compression load at strain rate of $10^{-3}, 10^{-2}$ and $10^{-1} \mathrm{~s}^{-1}$. A good agreement was obtained between the calculated and experimental results over different stages of deformation and hardening. Microstructural analysis was also carried out to relate the deformation results to the microstructure of the steels. Finally, a general constitutive equation has been proposed for hot deformation of steels in the intercritical zone.
\end{abstract}

Keywords: Hot deformation, modeling, constitutive equation, intercritical zone.

\section{Introduction}

Steel is one of the most researched materials, even though today certain aspects of its behavior under given conditions continue to be ambiguous, such as the hot deformation of steels ${ }^{1-4}$. There is considerable agreement regarding the impact of the elements $\mathrm{C}, \mathrm{Si}$ and $\mathrm{Mn}$ on the mechanical properties of carbon steels, especially when analyzing their behavior when subjected to cold work; however, there exist uncertainties with respect to the behavior of the aforementioned elements during deformation operations at high temperatures ${ }^{5}$. Given the multiplicity of variables involved in this type of operations (speed and type of deformation, temperature, active diffusion mechanisms, chemical composition, initial austenitic grain size, dislocation structure, energies of activation and failure $)^{6}$, it is expected that the analysis will become complex and that greater efforts will be required to distinguish or attribute the effect of the chemical composition ${ }^{4}$.

The phenomena involved in the processes of deformation at high temperatures are controlled by diffusion, movement of dislocations and atomic interaction with the environment. Examples of this include strain hardening and dynamic restoration phenomena ${ }^{7,8}$.

Carbon affects the hot behavior of steels depending on their possibilities of diffusion through the network and their interaction with other atoms and dislocations. However, this behavior is not entirely clear ${ }^{9-11}$. It is believed that the addition of $\mathrm{C}$ causes distortions in the crystal lattice, resulting in an increase in the kinetics of the self-diffusion mechanisms of

*e-mail: cancio.jimenezlugos@hotmail.com the matrix atoms. There is not an agreement in the literature about the effect of $\mathrm{C}$ on maximum yield stresses.

It has been observed that increasing the contents of $\mathrm{Si}$ and $\mathrm{Mn}$ increases the hardness such as in cold working processes. However, some results question whether both elements play a similar role in terms of softening mechanisms. Prasad et al. ${ }^{12}$ studied the modification of both the stacking fault energy and the activation energy necessary for the process. The addition of solute clearly limits the mobility and migration of grain boundaries of austenite, directly affecting the kinetics of recovery and dynamic recrystallization $1^{13,14}$.

Zener et al. ${ }^{15}$ tested brass alloy $\mathrm{CuZn}_{40} \mathrm{~Pb}_{2}$ in twophases and reported the deformation behavior in terms of temperature, strain rate and amount of phases. Bergstrom and Aronsson ${ }^{16}$ and Sakai and Jonas ${ }^{17}$ studied the hot creep behavior of so-called construction steels and their dependence on chemical composition by isothermal uniaxial compression. Sakai and Jonas ${ }^{17}$ reported that the flow curves of all ferritic materials show the characteristics of materials with dynamic recovery. The model of hot deformation reported and proposed by Estrin and Mecking ${ }^{18}$ shows good agreement with the experimental data. The hot-flow behavior was studied experimentally via isothermal uniaxial compression ${ }^{19,20}$, in a wide range of temperature and deformation velocities and the parameters were obtained in the intercritical interval, applicable to a generic constituent model of hot deformation.

The present study focuses on obtaining a generic constitutive modeling that predicts the hot deformation behavior of carbon steels in the intercritical zone $(\alpha+\gamma)$ in terms of the contents of $\mathrm{Fe}, \mathrm{C}, \mathrm{Mn}$ and $\mathrm{Si}$. The modeling process requires that the 
constitutive equation can predict the deformation process in terms of the parameters that govern the softening and hardening phenomena ${ }^{21,22}$. The proposed generic constitutive modeling is based on the law of mixtures of the deformation of austenite and ferrite, where the characteristic parameters are the function of the chemical composition, temperature, and strain rate. The present hot working characterization was performed by means of uniaxial compression test in a temperature range of 740 to $815^{\circ} \mathrm{C}$ and using strain rates from 0.1 to $0.001 \mathrm{~s}^{-1}$. The compression flow curves have been modeled by a physically based constitutive modeling that describing the hardening work, recovery phenomena, considering the amount of ferrite and austenite phases as a function of temperature and applied strain rate.

\section{Experimental}

\subsection{Theoretical procedure}

In the modelling of hot deformation process, the knowledge of stress-strain relationships for specific values of strain, strain rate and temperature for different materials is an essential requirement for quantitatively analyzing deformation processes such as rolling, forging, drawing, extrusion, etc. Many studies have been conducted to experimentally obtain flow curves using different testing techniques at isothermal and constant strain rate conditions ${ }^{23}$. However, unlike most laboratory tests, industrial hot working operations do not take place at isothermal and/or constant strain rate conditions. For example, in a hot rolling pass, temperature and strain rate change significantly, leading to a continuous variation of process conditions and process parameters throughout the pass.

In a typical analysis of deformation ${ }^{24,25}$ it is found that the strain rates and strains at different locations can vary by an order of magnitude and hence the flow stresses can easily vary when different elements in the deformation zone are considered. The problem becomes even more complex when thermal models are coupled with mechanical models resulting in a wide spectrum of strain-strain rate-temperature conditions in the deformation zone at any given time. Many researchers ${ }^{26,27}$ have focused their attention in developing quantitative constitutive relationships for describing the flow strength of materials as a function of the process variables such as strain, strain rate and temperature for use in process models.

Empirical and semi-empirical relationships obtained from experimental data are widely used in deformation models because they are easier to develop and complex internal material variables need not to be considered. However, due to complicated microstructural changes associated with high temperature deformation processing, it is very difficult to describe the complete hot deformation behavior using a single relationship. The relationships used often present flow strength in terms of either strain and strain rate or strain rate and temperature; the empirical constants are defined for different process conditions. While the equations relating stress and strain ${ }^{28}$ adequately describe the strain hardening portion of the flow curves, the equations relating stress to strain rate and temperature ${ }^{29-31}$ represent only the steady state deformation conditions. Equations in which all three process variables are related to flow stress ${ }^{32-36}$ have limited applicability beyond strain hardening part of the flow curves. Several other relationships ${ }^{37,38}$, or combination of the above relationships have been developed to describe the flow stress data in terms of the process variables.

The aim of this study was to model the plastic flow behavior in the intercritical zone $(\alpha+\gamma)$ according Fe-C diagram, in hot working conditions with two steel 1008 and 1035, first determining the models in the austenitic and ferritic zone with previous validation of the curves and later comparing them with the experimental stress-strain curves at the same conditions of temperature and strain rate. Figure 1 shows the flow chart for the theoretical and experimental procedure. A list of the parameters used in the model is shown in Appendix A.

If the criteria and the flow curves obtained in the austenitic ${ }^{2}$ and ferritic ${ }^{5}$ zones are already known, the modeling of the creep curve can be obtained in the intercritical zone by means of the mixing law, making a balance of the formulas used in these models. The model considers that the dislocations density $\rho$ is caused by the balance between generation and storage dislocations during work hardening and annihilation during dynamic recovery and also that the EM is only applicable in fine-grain materials or those bearing fine second phase particles. This model relates the density of dislocations with the deformation is written as:

$$
\frac{d \rho}{d \varepsilon}=\left[\frac{d \rho}{d \varepsilon}\right]_{\text {stored }}-\left[\frac{d \rho}{d \varepsilon}\right]_{\text {recovered }}
$$

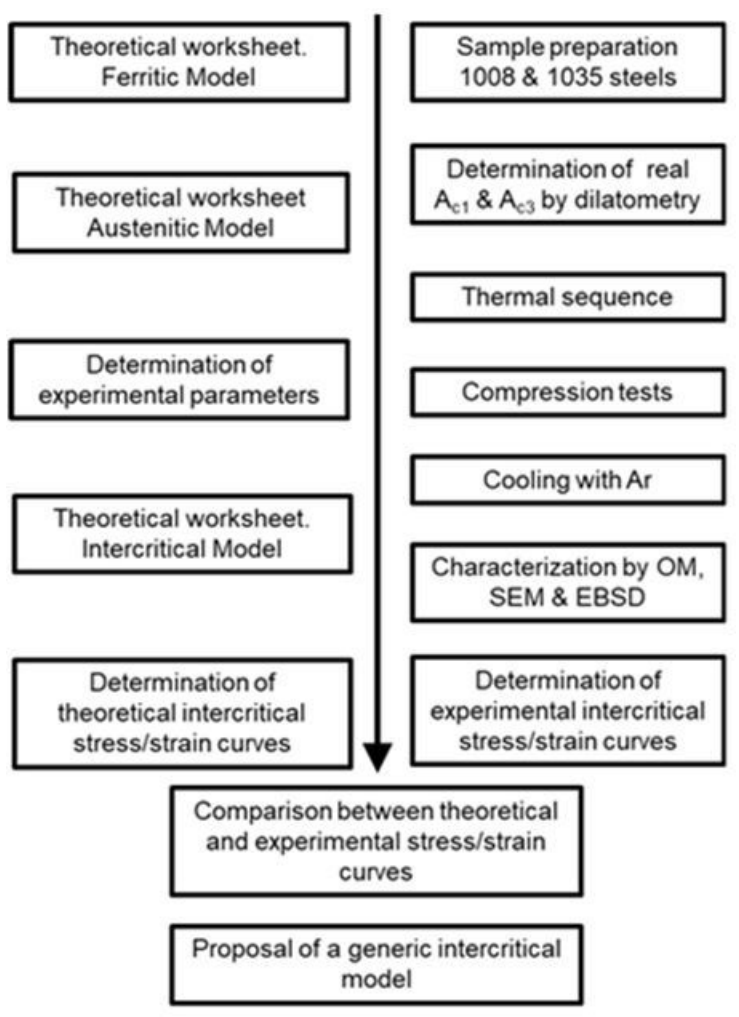

Figure 1. Theoretical and experimental flow diagram. 
where $\rho$ is the density of dislocations $\left(\mathrm{cm}^{-2}\right)$ and $\varepsilon$ is the strain rate $\left(\mathrm{s}^{-1}\right)$.

The equation of stress in terms of the deformation and the strain rate and temperature is:

$\theta=\left[\frac{d \sigma}{d \varepsilon}\right]_{\varepsilon, 1}$

This equation can be solved by integration:

$\rho(\varepsilon)=e^{-\int \Omega(\varepsilon) d \varepsilon} \cdot \int e^{\int \Omega(\varepsilon) d \varepsilon} \cdot U(\varepsilon) d \varepsilon+e^{-\int \Omega(\varepsilon) d \varepsilon} \cdot C_{1}$

where $\Omega$ is the coefficient of softening or dynamic restoration and $\mathrm{U}$ is the coefficient of hardening.

The evolution of stress during deformation can be expressed as:

$\sigma=\alpha \mathrm{M} \mu \mathrm{b} \sqrt{\rho}$

where $\alpha$ is a constant, M Taylor factor, $\mu$ is the shear module and $\mathrm{b}$ is the Burgers vector.

The creep behavior of materials during dynamic restoration can be expressed as:

$\frac{d \rho}{d \varepsilon}=U-\Omega \rho$

If $U$ and $\Omega$ are independent of deformation $(\varepsilon)$, then:

$\sigma=\left[\sigma_{0}^{2} e^{-\Omega \varepsilon}+(\alpha \mu b)^{2}\left(\frac{U}{\Omega}\right)\left(1-e^{-\Omega \varepsilon}\right)\right]^{0.5}$

Or

$\sigma^{2}=\left[\sigma_{S}^{2}+\left(\sigma^{2}-\sigma_{S}^{2}\right) e^{-\Omega \varepsilon}\right]$

$\sigma_{0}=\alpha \mu b \sqrt{\rho}$

$\sigma_{s}=\alpha \mu b \sqrt{\frac{U}{\Omega}}$

In the case of DRX (dynamic recrystallization), $\sigma$ is represented by the expression of Avrami:

$\sigma=\sigma_{s}-\left(\sigma_{s}-\sigma_{s s}\right) \cdot \boldsymbol{X}$

$\boldsymbol{X}=1-\exp \left[-\boldsymbol{B} \boldsymbol{t}^{\boldsymbol{k}}\right]=1-\exp \left[-0.693\left(\frac{\boldsymbol{t}}{\boldsymbol{t}_{50 \%}}\right)^{\boldsymbol{k}}\right]$

where $\mathrm{B}$ and $\mathrm{k}$ are constants associated to the nucleation mechanisms and the growth velocity, $\mathrm{X}$ is the recrystallized volumetric fraction.

The kinetic equation for peak deformation is expressed as:

$$
\varepsilon_{C}=0.8 \cdot \varepsilon_{P}=K_{\varepsilon} \cdot d_{0}^{n_{s}} \cdot Z^{m_{s}}
$$

where $d_{0}$ is the initial grain size, $\mathrm{Z}$ is the parameter of Zener Hollomon, $\mathrm{K}$ is a constant of the material.

For the case of stress and steady state peak it is obtained:

$$
\frac{\dot{\varepsilon}}{D(T)}=A\left(\sinh \frac{\alpha \sigma_{p}}{E(T)}\right)^{5}
$$

Where E (T) is the Young's modulus, D (T) is the self-diffusion coefficient, $\sigma_{\mathrm{p}}$ is the peak stress, $\alpha$ phase $\alpha, \mathrm{A}$ is a material constant and $\dot{\varepsilon}$ is the strain rate. The coefficient of softening or restoration is as given as:

$\Omega=K \Omega \cdot d_{0}^{n_{\Omega}} \cdot Z^{m_{\Omega}}$

The coefficient of hardening is:

$(\alpha b)^{2} U=K_{U} \cdot d_{0}^{n_{U}} \cdot Z^{m_{U}}$

where $\mathrm{K}_{\Omega}$ and $\mathrm{K}_{\mathrm{U}}$ are constants of the materials.

The recrystallization time is given $\mathrm{b}$ :

$T_{50 \%}=K_{t} \cdot d_{0}^{m_{t}} \cdot \varepsilon^{n_{t}} \cdot \exp \left(\frac{Q_{t}}{R T}\right)$

where $\mathrm{T}_{50 \%}$ is the time taken to reach $50 \%$ recrystallization, $\mathrm{K}_{\mathrm{t}}$ is a constant material, $\mathrm{Q}$ is the activation energy, $\mathrm{R}$ is the gas constant and $\mathrm{T}$ is absolute temperature.

\subsubsection{Generic model for Fe-C-Mn-Si alloys in the intercritical zone $(\alpha+\gamma)$}

The present model is based on a generic model for calculating the hot flow stress in the ferritic and austenitic zone $(\alpha+\gamma)^{1,3}$, and is used to study Fe-C-Mn-Si alloys in the dual phase intercritical zone $(\alpha+\gamma)$.

The strain rate for a single phase is expressed as follows ${ }^{1}$ :

$$
\left\{\frac{\dot{\varepsilon}}{D(T)}\right\}=B\left(\sinh \frac{\beta \sigma}{E(T)}\right)^{n}
$$

where $\dot{\varepsilon}$ is the strain rate, $\mathrm{D}(\mathrm{T})$ is the diffusion coefficient affected by temperature, $\mathrm{B}$ is a structural parameter, $\beta$ is the parameter that is equal to the inverse of the voltage and represents the dependency change between the strain rate and the stress. $\sigma$ is true stress, E (T) is Young's modulus affected by temperature and $\mathrm{n}$ is the exponential factor. In dual phase zones and considering the law of mixtures, the equation becomes:

$\left\lceil\frac{\dot{\varepsilon}}{\% \alpha D_{\alpha}(T)+\% \gamma D_{\gamma}(T)}\right]=\left(\% \alpha B_{\alpha}+\% \gamma B_{\gamma}\right)\left[\sinh \frac{\left(\% \alpha \gamma_{\alpha}+\% \gamma \gamma_{\gamma}\right) \sigma}{\% \alpha E_{\alpha} T+\% \gamma E_{\gamma}(T)}\right]^{n}$

In this research, this equation is only applied considering the percentages of each of phase present as a function of the temperature, strain rate, and chemical composition of the alloy, therefore it does not consider the strain and stress distribution between phases ${ }^{39,40}$. In the future, it is possible to compare these results considering the effects of this phenomenon for this kind of steel.

The percent of the present phases is determined by the lever rule and then the composition of the ferrite and the austenite depends on the temperature and the global chemical composition.

Therefore, $\sigma$ is expressed as:

$\sigma=\left[\frac{\% \alpha E_{\alpha}(T)+\% \gamma E_{\gamma}(T)}{\% \alpha \gamma_{\alpha}+\% \gamma \gamma_{\gamma}}\right] \sinh \left[\left(\frac{\dot{\varepsilon}}{\% \alpha D_{\alpha}+\% \gamma D_{\gamma}}\right)^{\frac{1}{n}}\left(\frac{1}{\left(\% \alpha B_{\alpha}+\% \gamma B_{\gamma}\right)^{\frac{1}{n}}}\right)\right]$ 


\subsection{Experimental procedure}

Two commercial steels $\mathbf{1 0 0 8}$ and $\mathbf{1 0 3 5}$ were selected because present a wide intercritical interval $(\alpha+\gamma)$. Table 1 shows the chemical composition of the chosen steels.

For hot compression tests, a BÄHR DIL 805A / D brand dilatometer was used to operate under two different modes: "Dilatometer mode" and "Deformation mode", It was equipped with tools or push rods (silica and aluminum) and a protecting Ar atmosphere. This entire cycle has been worked in a controlled Argon atmosphere to avoid oxidation of the samples. Molybdenum was used on both faces of the samples as a lubricant to reduce friction and a high flow of Argon to quench them. The dilatometric curves were obtained using solid cylindrical specimens with $5 \mathrm{~mm}$ diameter and $10 \mathrm{~mm}$ height, using a K-type thermocouple welded in the center. The heating and cooling rate was $2{ }^{\circ} \mathrm{C} / \mathrm{s}$ and $10^{\circ} \mathrm{C} / \mathrm{s}$ respectively.

The dilatometer in the "Dilatometer mode" was used to estimate the intercritical temperatures of coexistence of the phases $(\alpha+\gamma)$ for each kind of steel. Figure 2 shows the elongation-temperature during cooling and heating. The characteristic temperatures obtained are summarized in Table 2, where

$A_{1}$ : Temperature for the lower boundary of the $\alpha+\gamma$ range;

$A_{3}$ : Temperature for the upper boundary of the $\alpha+\gamma$ range;

$\mathrm{Ac}_{1}$ : Temperature at which austenite formation starts during heating;

$\mathrm{Ar}_{1}$ : Temperature at which austenite disappears during cooling;

$\mathrm{Ac}_{3}$ : Temperature at which austenite formation is completed during heating;

$\mathrm{Ar}_{3}$ : Temperature at which austenite starts to transform to ferrite during cooling;

$\mathrm{T}_{\max }$ Maximum test temperature; and

Table 1. Chemical composition of the 1008 and 1035 steels (mass \%).

\begin{tabular}{cccccc}
\hline Steel & $\mathbf{\% C}$ & $\mathbf{\% S i}$ & $\mathbf{\% M n}$ & $\mathbf{\% P}$ & $\mathbf{\% S}$ \\
\hline 1008 & 0.075 & 0.145 & 0.351 & 0.035 & 0.034 \\
\hline 1035 & 0.308 & 0.251 & 0.787 & 0.042 & 0.035 \\
\hline
\end{tabular}

$\mathrm{T}_{\min }:$ Minimum test temperature.

The experimental temperatures for the deformation tests were established from the dilatometer results ( $\mathrm{Ac}_{1}$ and $\mathrm{Ac}_{3}$ ). These temperatures and the strain rate used in the experimental procedure are shown in Table 3.

The thermal cycle established for hot compression tests can be divided into six different stages, as shown in Figure 3:

1. Heating to total solubilization temperature of austenite;

2. Maintenance at that temperature;
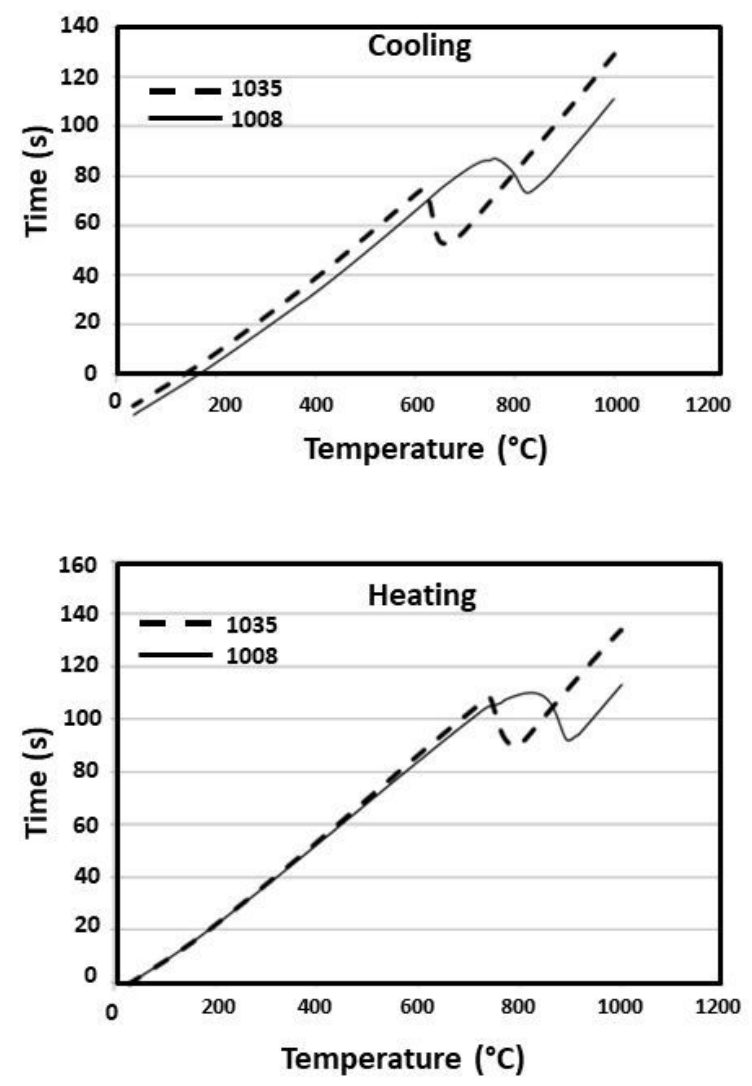

Figure 2. Heating and cooling curves obtained by Dilatometry.

Table 2. Heating and cooling temperatures according to Dilatometer tests.

\begin{tabular}{ccccccccc}
\hline & \multicolumn{8}{c}{ Temperature $\left({ }^{\circ} \mathbf{C}\right)$} \\
\cline { 2 - 10 } & $\mathbf{A}_{\mathbf{3}}$ & $\mathbf{A}_{\mathbf{1}}$ & $\mathbf{A c}_{\mathbf{3}}$ & $\mathbf{A c}_{\mathbf{1}}$ & $\mathbf{A r}_{\mathbf{3}}$ & $\mathbf{A r}_{\mathbf{1}}$ & $\mathbf{T}_{\text {MAx }}$ & $\mathbf{T}_{\text {MIN }}$ \\
\hline 1008 Steel & 877 & 723 & 903 & 805 & 837 & 751 & 815 & 770 \\
\hline 1035 Steel & 820 & 723 & 797 & 732 & 678 & 611 & 785 & 740 \\
\hline
\end{tabular}

Table 3. Experimental conditions.

\begin{tabular}{cccccc}
\hline \multirow{2}{*}{ STEEL } & $\dot{\varepsilon}$ & \multicolumn{4}{c}{ Temperature $\left({ }^{\circ} \mathbf{C}\right)$} \\
\hline \multirow{3}{*}{$\mathbf{1 0 0 8}$} & $10^{-3}$ & 815 & 800 & 785 & 770 \\
\cline { 2 - 6 } & $10^{-2}$ & 815 & 800 & 785 & 770 \\
\cline { 2 - 6 } & $10^{-1}$ & 815 & 800 & 785 & 770 \\
\hline \multirow{2}{*}{$\mathbf{1 0 3 5}$} & $10^{-3}$ & 785 & 770 & 755 & 740 \\
& $10^{-2}$ & 785 & 770 & 755 & 740 \\
\cline { 2 - 6 } & $10^{-1}$ & 785 & 770 & 755 & 740 \\
\hline
\end{tabular}


3. Cooling to test temperature;

4. Maintenance at given temperature for homogenization of the microstructure;

5. Compression test; and

6. Sample tempering.

\section{Results and Discussion}

Once the ferritic and austenitic model had been theoretically reproduced, they were validated with the deformation curves obtained. The percentages were subsequently determined for each phase by the lever rule at the test temperatures (Table 4). The constant's values ${ }^{1-3}$ used in the generic model represents average values to the same conditions in austenitic and ferritic model which are shown in Table 5.

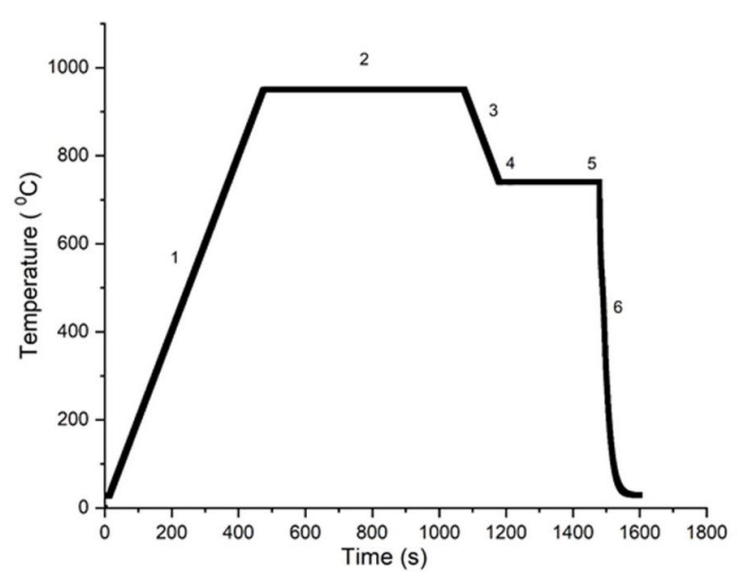

Figure 3. Test stages.
The intercritical parameters of the model were calculated by the following way:

$$
\begin{aligned}
& E(T)_{I}=E(T)_{\alpha} \% X_{\alpha}+E(T)_{\gamma} \% X_{\gamma} \\
& D(T)_{I}=D(T)_{\alpha} \% X_{\alpha}+D(T)_{\gamma} \% X_{\gamma} \\
& B_{I}=B_{\alpha} \% X_{\alpha}+B_{\gamma} \% X_{\gamma} \\
& \beta_{I}=\beta_{\alpha} \% X_{\alpha}+\beta_{\gamma} \% X_{\gamma} \\
& \Omega_{I}=\Omega_{\alpha} \% \alpha+\Omega_{\gamma} \% \gamma \\
& U_{I}=U_{\alpha} \% \alpha+U_{\gamma} \% \gamma \\
& \sigma_{I}=\sigma_{\alpha} \% X_{\alpha}+\sigma_{\gamma} \% X_{\gamma}
\end{aligned}
$$

where $\sigma_{I}$ is the intercritical stress and represented the peak stress $\left(\sigma_{p}\right)$ or steady stress $\left(\sigma_{s s}\right)$.

\subsection{Flow curve}

In the quenching process, the sample, hollow or solid, is inductively heated to a temperature plateau and is then cooled at a user-defined (exponential or linear) cooling rate. The phase transformation occurring in the continuous cooling process or in the isothermal dwell, with or without compression, is specified by the measured variation in length. An array of isothermal or cooling curves indicates an

\begin{tabular}{|c|c|c|c|c|c|c|}
\hline \multirow{2}{*}{$\begin{array}{c}\text { LOW CARBON } \\
\text { STEEL } \\
{ }^{\circ} \mathrm{C} \\
\end{array}$} & \multicolumn{2}{|c|}{ COMPOSITION } & \multicolumn{2}{|c|}{$\begin{array}{l}\text { THEORICAL FRACTION } \\
\text { EXPERIMENTAL }\end{array}$} & \multicolumn{2}{|c|}{$\begin{array}{c}\text { IMAGE ANALIZER IQ } \\
\text { MATERIALS }\end{array}$} \\
\hline & $\alpha$ & $\gamma$ & $\% \alpha$ & $\% \gamma$ & $\% \alpha$ & $\% \gamma$ \\
\hline 815 & 0.002 & 0.325 & 78 & 22 & 85 & 16 \\
\hline 800 & 0.003 & 0.375 & 81 & 19 & 87 & 13 \\
\hline 785 & 0.005 & 0.420 & 83 & 17 & 88 & 12 \\
\hline 770 & 0.006 & 0.490 & 86 & 14 & 90 & 10 \\
\hline \multicolumn{7}{|l|}{$\begin{array}{l}\text { MEDIUM } \\
\text { CARBON } \\
\text { STEEL }\end{array}$} \\
\hline 785 & 0.005 & 0.420 & 27 & 73 & 26 & 74 \\
\hline 770 & 0.006 & 0.490 & 39 & 61 & 38 & 62 \\
\hline 755 & 0.008 & 0.540 & 47 & 53 & 42 & 58 \\
\hline 740 & 0.010 & 0.640 & 53 & 47 & 45 & 55 \\
\hline
\end{tabular}
isothermal time-temperature-transformation (TTT) diagram or a continuous-cooling-transformation (CCT) diagram,

\begin{tabular}{|c|c|c|c|}
\hline \multicolumn{2}{|c|}{ Ferrite } & \multicolumn{2}{|c|}{ Austenite- $\sigma_{p}$} \\
\hline$B^{1 / 5}$ (Alfa) & $\beta($ Alfa $)$ & $\mathrm{B}^{1 / 5}$ (Austenite) & $\beta$ (Austenite) \\
\hline 603.936 & 1175.1458 & 348.15 & 618.71 \\
\hline \multicolumn{2}{|c|}{ Ferrite } & \multicolumn{2}{|c|}{ Austenite- $\sigma_{\mathrm{ss}}$} \\
\hline$B^{1 / 5}$ (Alfa) & $\beta($ Alfa $)$ & $B^{1 / 5}$ (Austenite) & $\beta$ (Austenite) \\
\hline 603.936 & 1175.1458 & 274.588 & 779.71 \\
\hline
\end{tabular}
respectively. The flow tests were carried out under the protective Ar atmosphere and, in order to minimize friction between the tools of the machine and the specimen, wolfram

Table 4. Experimental and theoretical values of the phases and their chemical composition at the test temperatures.

Table 5. Constants used in the generic model. 
sheets were used, each test was carried out until a true strain was obtained-a maximum of 0.8 - with the aim of minimizing the possible heterogeneities in strain. In these conditions, friction is considered minimum and the flow curves are not corrected by heating.

It can be observed that the mean size of the grains for all the alloys, given in Table 6, was about $38.125 \mu \mathrm{m}$ with a mean standard deviation of $\pm 10 \mu \mathrm{m}$, and thus it is assumed that the effect of this parameter on the creep behavior is negligible.

Figures 4 and 5 show strain curves obtained by experimental compression at different temperatures and strain rates to medium carbon steel (1035) and low carbon steel (1008),
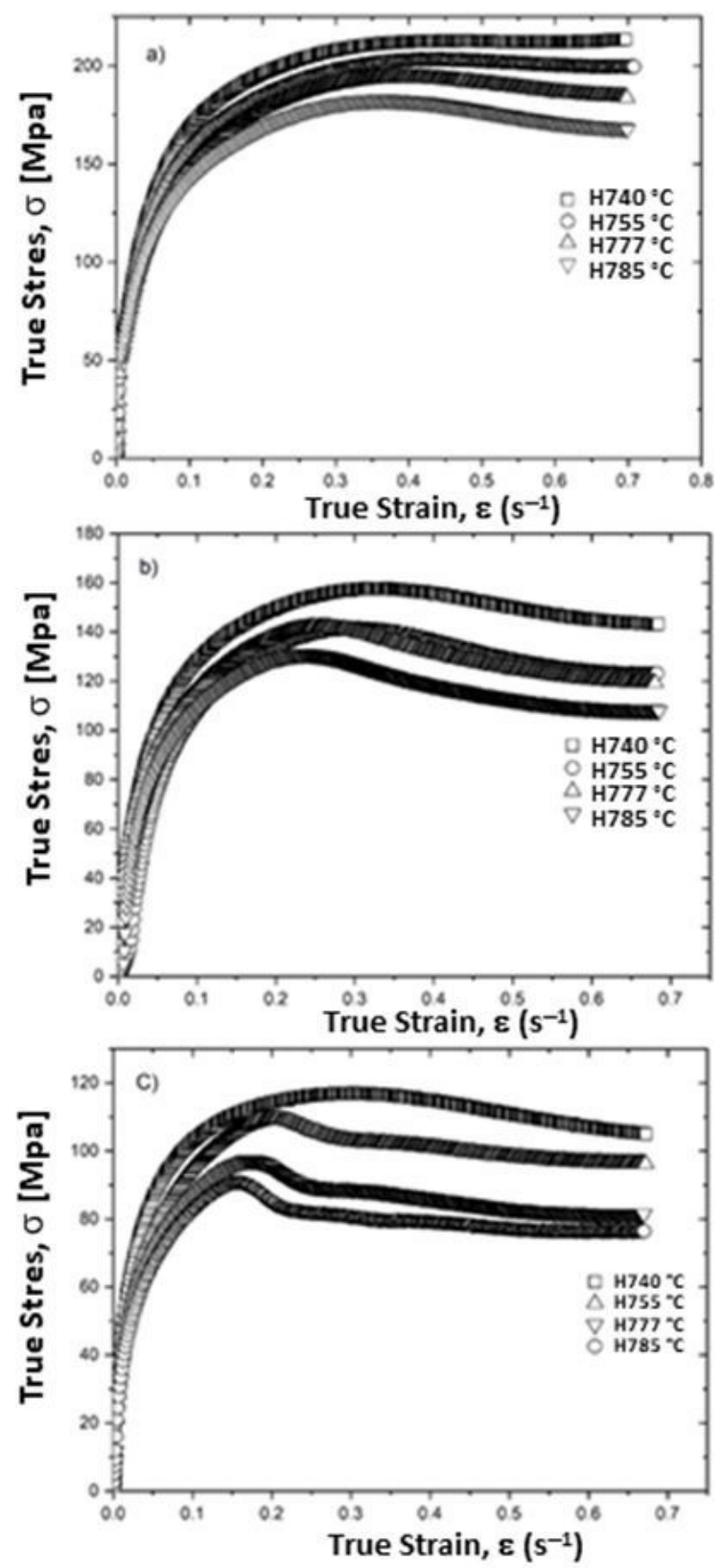

Figure 4. Experimental compression strain curves at different temperatures and strain rate of a) $0.1 \mathrm{~s}^{-1}$, b) $0.01 \mathrm{~s}^{-1}$, and c) 0.001 $\mathrm{s}^{-1}$ medium carbon steel. respectively. In general terms the materials progressively soften to a steady stress level $\left(\sigma_{\mathrm{ss}}\right)$ after reaching the maximum stress $\left(\sigma_{\mathrm{p}}\right)$. Figure 6 shows the comparison of the experimental

Table 6. Mean values of the grain sizes for the test conditions.

\begin{tabular}{ccccc}
\hline \multicolumn{5}{c}{ STEEL 1008 } \\
\hline Temperature $\left({ }^{\circ} \mathbf{C}\right)$ & 770 & 785 & 800 & 815 \\
\hline $\mathbf{d}_{\mathbf{0}}(\mu \mathrm{m})$ & 36 & 37 & 39.8 & 46.9 \\
\hline \multicolumn{5}{c}{ STEEL $\mathbf{1 0 3 5}$} \\
\hline Temperature $\left({ }^{\circ} \mathbf{C}\right)$ & 740 & 755 & 770 & 785 \\
\hline $\mathbf{d}_{\mathbf{0}}(\mu \mathrm{m})$ & 33.5 & 35.8 & 37.5 & 38.5 \\
\hline
\end{tabular}
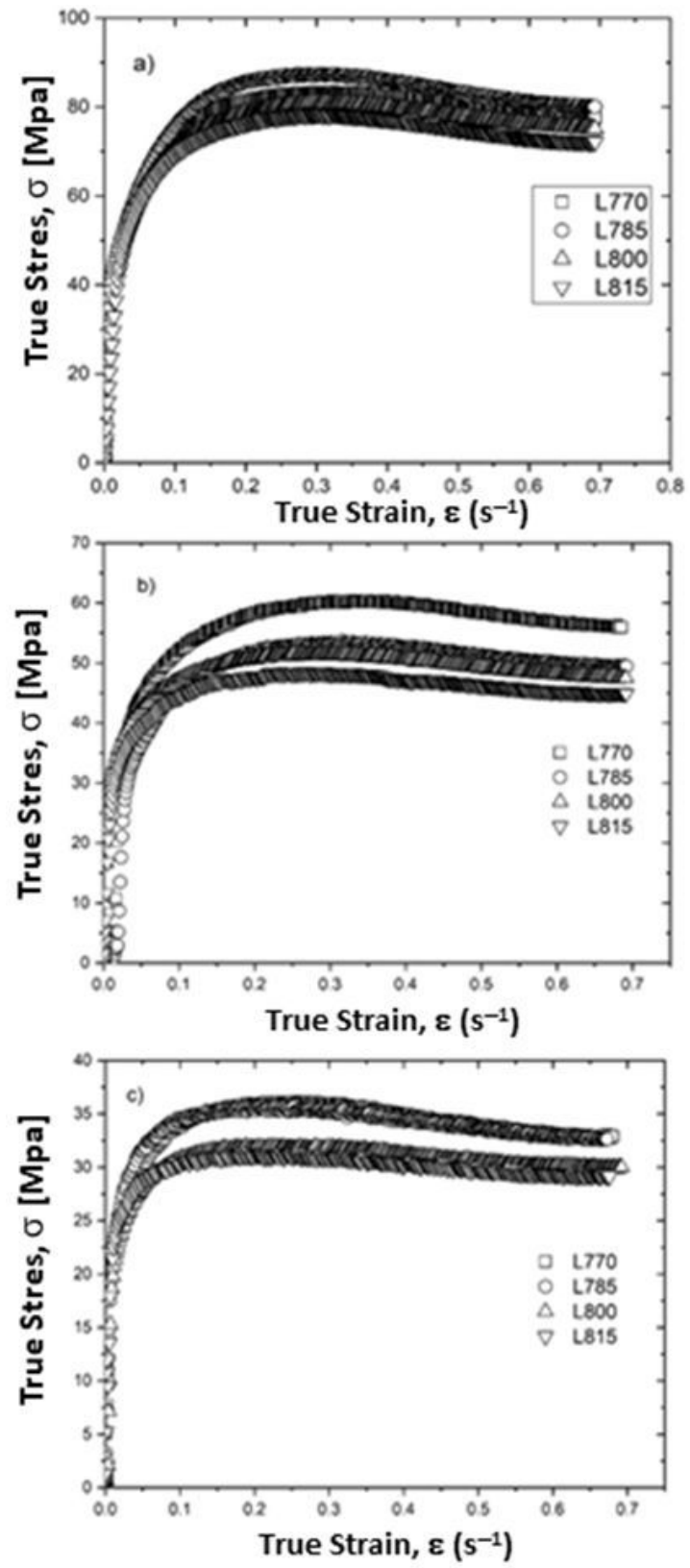

Figure 5. Experimental compression strain curves at different temperatures and strain rate, a) $0.1 \mathrm{~s}^{-1}$, b) $0.01 \mathrm{~s}^{-1}$, and c) $0.001 \mathrm{~s}^{-1}$ low carbon steel. 
and predicted results flow curves at different temperatures and strain rate, a) $0.1 \mathrm{~s}^{-1}$, b) $\left.0.01 \mathrm{~s}^{-1}, \mathrm{c}\right) 0.001 \mathrm{~s}^{-1}$ for low and
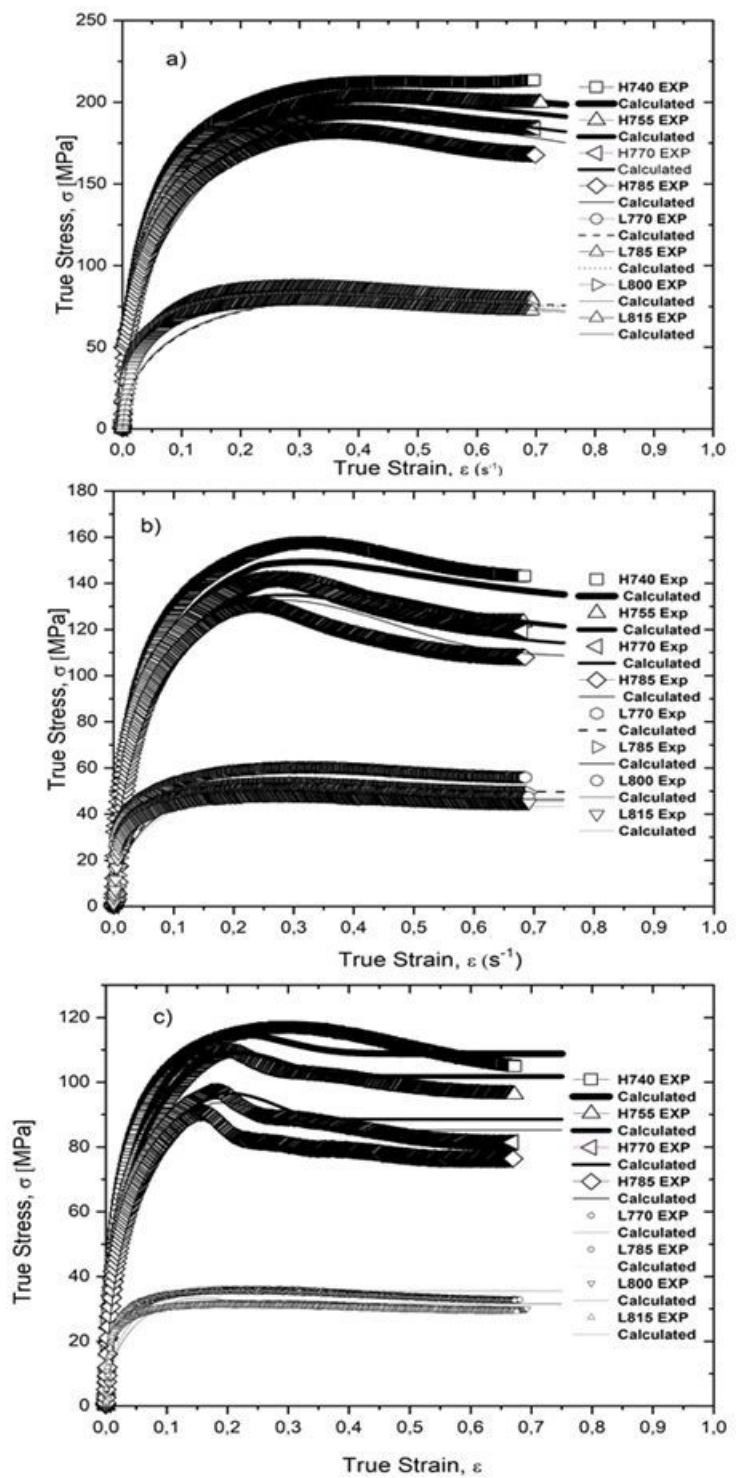

Figure 6. Comparison between experimental (points) and predicted (solid lines), flow curves at different temperatures and strain rate, a) $\left.0.1 \mathrm{~s}^{-1}, \mathrm{~b}\right) 0.01 \mathrm{~s}^{-1}$, c) $0.001 \mathrm{~s}^{-1}$ Low and medium carbon steel. medium carbon steel. Figure 7 shows the behavior of two curves that are crossed at the maximum peak stress, which is probably due to the change in magnetic properties.

Table 7 shows the comparison of the following peak stress parameters obtained by the experimental and theoretical curves:

$\sigma_{\mathrm{PE}}$ Experimental Peak Stress;

$\sigma_{\mathrm{PT}}$ Theoretical Peak Stress;

$\varepsilon_{\mathrm{PE}}$ Experimental Peak Strain; and

$\varepsilon_{\mathrm{PT}}$ Theoretical peak strain.

Figure 8 shows the comparison between the calculated results, applying intercritical generic model and the experimental curves $\left(\sigma_{\mathrm{PT}} \mathrm{VS} \sigma_{\mathrm{PE}}\right)$, thereby demonstrating the reliability of the proposed model.

\subsection{Metallography microstructures}

In steels with low carbon content, when austenite is cooled at high speed, it transforms without a diffusion process, producing martensite. The cooling rate necessary to produce martensite in this type of steels are enough high that the atoms do not have time to diffuse, so the transformation occurs through the movement of a large number of atoms. Therefore, martensite is a solid solution, supersaturated carbon-in-iron with a body-centered tetragonal crystal structure.

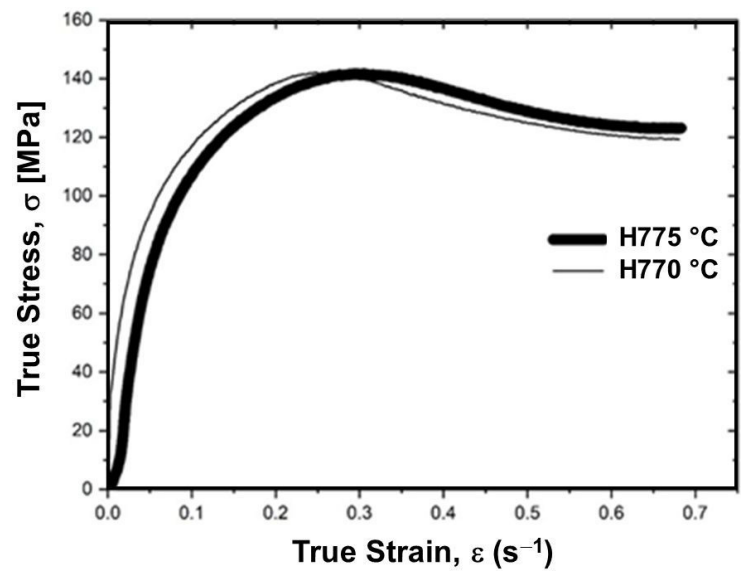

Figure 7. Intersection between 2 experimental curves at $755^{\circ} \mathrm{C}$ and $770^{\circ} \mathrm{C}$ at strain rate $0.01 \mathrm{~s}^{-1}$ for medium carbon steel.

Table 7. Peak and steady state stress to different strain rate.

\begin{tabular}{|c|c|c|c|c|c|c|c|c|c|c|c|c|c|}
\hline \multirow[b]{3}{*}{ Steel } & \multirow[b]{3}{*}{$\mathbf{T}\left({ }^{\circ} \mathbf{C}\right)$} & \multicolumn{12}{|c|}{ STRAIN RATE } \\
\hline & & \multicolumn{4}{|c|}{$10^{-3} s^{-1}$} & \multicolumn{4}{|c|}{$10^{-2} \mathrm{~s}^{-1}$} & \multicolumn{4}{|c|}{$10^{-1} s^{-1}$} \\
\hline & & $\begin{array}{c}\sigma_{\mathrm{PE}} \\
\text { (Mpa) }\end{array}$ & $\begin{array}{c}\sigma_{\mathrm{PT}} \\
(\mathbf{M p a})\end{array}$ & $\varepsilon_{\mathrm{PE}}\left(\mathrm{s}^{-1}\right)$ & $\varepsilon_{\mathrm{PT}}\left(\mathrm{s}^{-1}\right)$ & $\begin{array}{c}\sigma_{\mathrm{PE}} \\
\text { (Mpa) }\end{array}$ & $\begin{array}{c}\sigma_{\mathrm{PT}} \\
\text { (Mpa) }\end{array}$ & $\varepsilon_{\mathrm{PE}}\left(\mathbf{s}^{-1}\right)$ & $\varepsilon_{\mathrm{PT}}\left(\mathrm{s}^{-1}\right)$ & $\begin{array}{c}\sigma_{\mathrm{PE}} \\
\text { (Mpa) }\end{array}$ & $\begin{array}{c}\sigma_{\mathrm{PT}} \\
(\mathbf{M p a})\end{array}$ & $\varepsilon_{\mathrm{PE}}\left(\mathrm{s}^{-1}\right)$ & $\varepsilon_{\mathrm{PT}}\left(\mathbf{s}^{-1}\right)$ \\
\hline \multirow{4}{*}{1035} & 740 & 117 & 103 & 0.28 & 0.21 & 159 & 148 & 0.31 & 0.27 & 212 & 207 & 0.37 & 0.37 \\
\hline & 755 & 109 & 99 & 0.19 & 0.21 & 142 & 142 & 0.27 & 0.27 & 203 & 203 & 0.38 & 0.38 \\
\hline & 770 & 98 & 96 & 0.18 & 0.2 & 142 & 138 & 0.25 & 0.26 & 195 & 195 & 0.37 & 0.37 \\
\hline & 785 & 90 & 90 & 0.15 & 0.19 & 132 & 132 & 0.23 & 0.28 & 183 & 183 & 0.33 & 0.35 \\
\hline \multirow{4}{*}{1008} & 770 & 36 & 36 & 0.18 & 0.19 & 61 & 63 & 0.25 & 0.25 & 84 & 77 & 0.27 & 0.32 \\
\hline & 785 & 35.2 & 35 & 0.15 & 0.16 & 53.4 & 52 & 0.25 & 0.25 & 83.5 & 75 & 0.23 & 0.28 \\
\hline & 800 & 31.7 & 33 & 0.18 & 0.16 & 51.2 & 50 & 0.25 & 0.26 & 80.7 & 73 & 0.25 & 0.3 \\
\hline & 815 & 31.2 & 32 & 0.17 & 0.14 & 48.6 & 48 & 0.24 & 0.24 & 78.8 & 72 & 0.26 & 0.27 \\
\hline
\end{tabular}


The structure of martensite has the appearance of sheets or needles. The white phase is austenite that does not transform during rapid quenching. Martensite can also coexists with other constituents, such as pearlite. If there is diffusion, then ferrite and cementite phases will be formed.

Figures 9 and 10 show micrographs of the quenching samples of high and low carbon steels, respectively, at the same

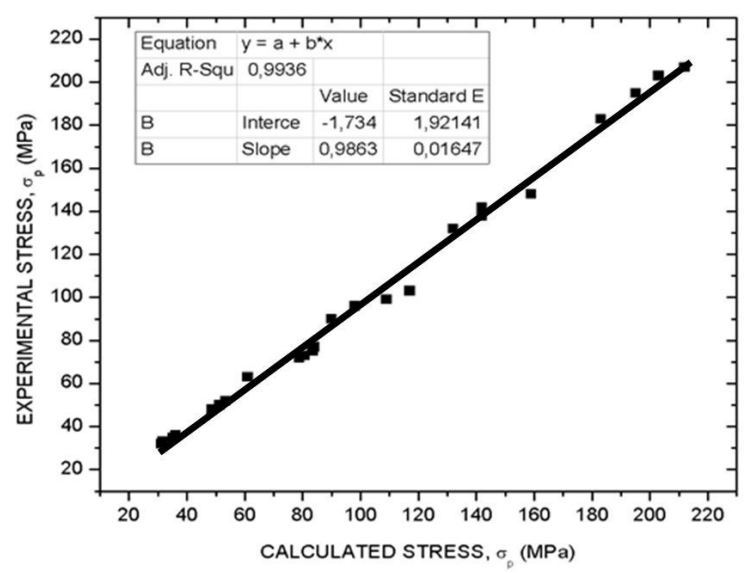

Figure 8. Comparison between theoretical and experimental peak stress.

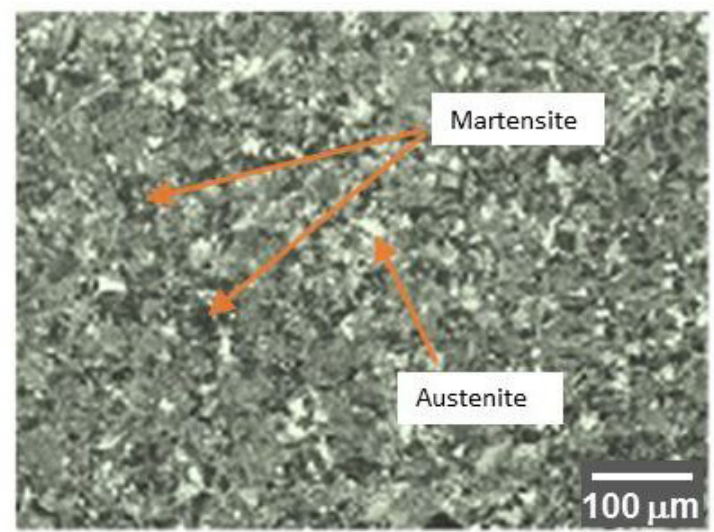

(a)

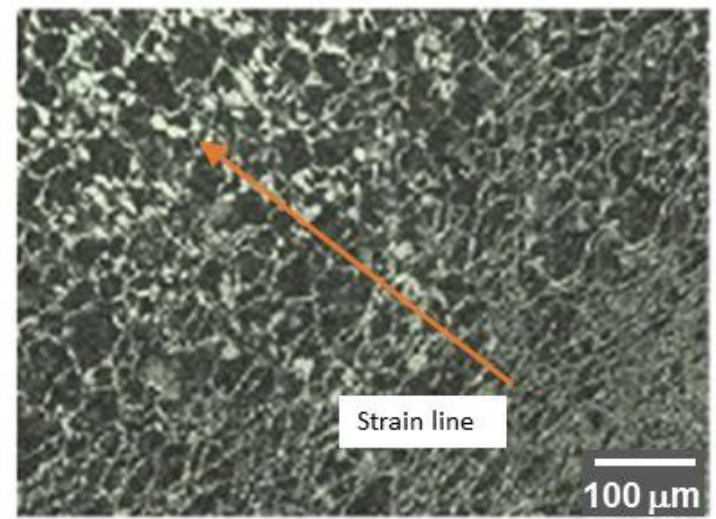

(c) magnifications and treated at different strain rates. austenite is in the white grains, while black grains are martensite, Figures 9a and 10a. It is observed that at higher strain rate, a smaller grain size is obtained, Figures $9 \mathrm{~b}$ and $10 \mathrm{~b}$, due to the higher speeds the grain size is prevented to increase. A higher grain size is observed in Figures 9d and 10d. The grain orientation is shown in Figures 9b, 9c, 9d, and 10b which is observed by the strain line.

Figure 11 shows the sample of the 1008 steel deformed at $800^{\circ} \mathrm{C}$ and a strain rate of $10^{-1} \mathrm{~s}^{-1}$, where a microstructure with a Ferrite matrix with black polymorphic grains is observed with a small amount of martensite sheets and small needles. Figures 12 shows the microstructure 1008 steel deformed at $800^{\circ} \mathrm{C}$ a strain rate of $10^{-2} \mathrm{~s}^{-1}$. Slightly more deformed and larger grains are observed as strain rate was decreased. The structure represents martensite in ferritic matrix.

From figures 13 to 15 is showed the microstructures obtained for the samples of the 1035 steel deformed at $785^{\circ} \mathrm{C}$ and strain rate of $10^{-1}, 10^{-2}$ and $10^{-3} \mathrm{~s}^{-1}$, respectively. These figures show a greater presence of martensite needles in polymorphic austenitic matrix. The grain growth is observed by decreasing strain rate. Figure 16 shows the microstructure of 1008 steel deformed at $800^{\circ} \mathrm{C}, 1000 \mathrm{X}$ and $4000 \mathrm{X}$, and a strain rate $10^{-2} \mathrm{~s}^{-1}$. These figures show a presence of martensite needles in polymorphic Ferritic matrix.

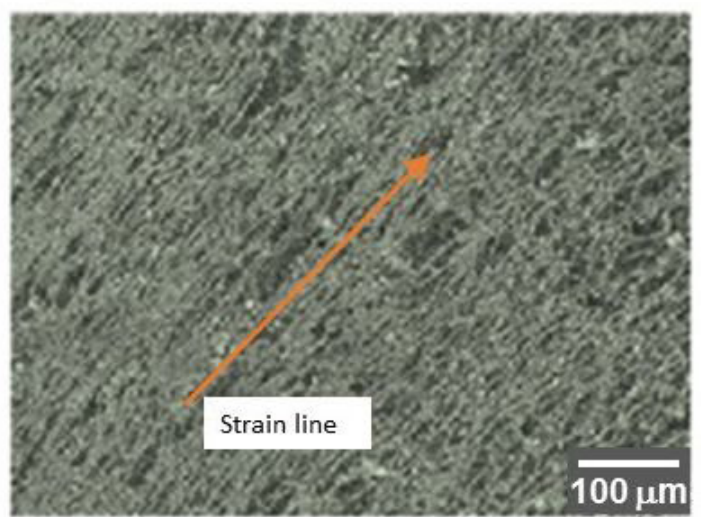

(b)

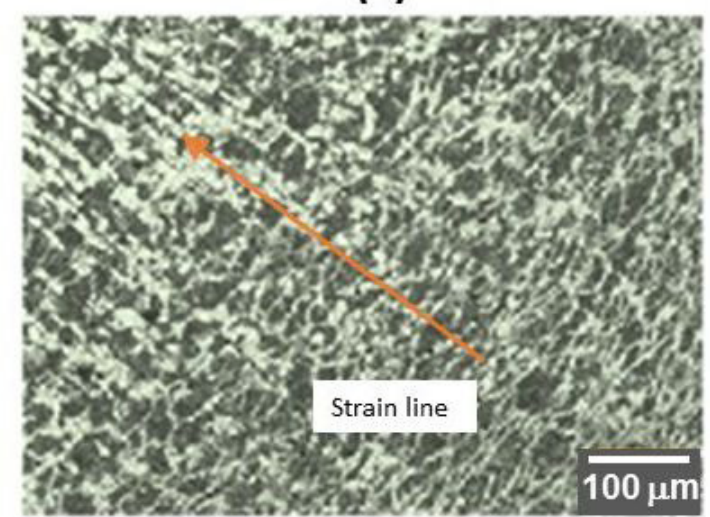

(d)

Figure 9. Medium carbon steel at $740{ }^{\circ} \mathrm{C}, 100 \mathrm{X}$ (a) Alone quenched (b) Strain rate $0.1 \mathrm{~s}^{-1}$, (c) $0.01 \mathrm{~s}^{-1}$ and (d) $0.001 \mathrm{~s}^{-1}$. 


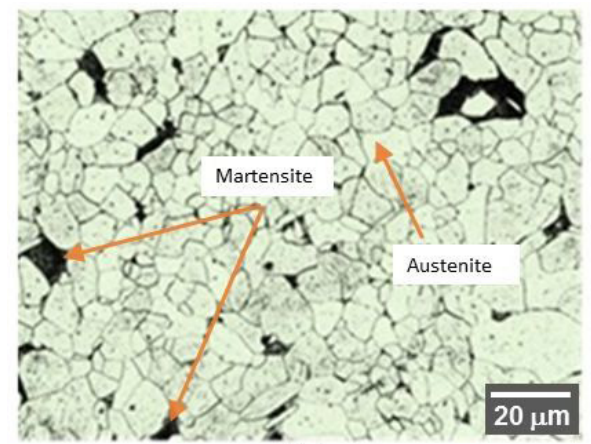

(a)

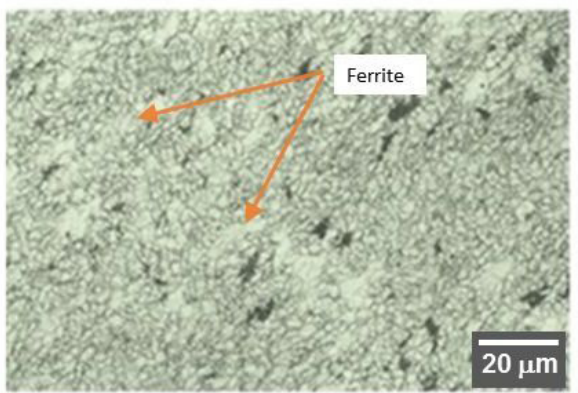

(c)

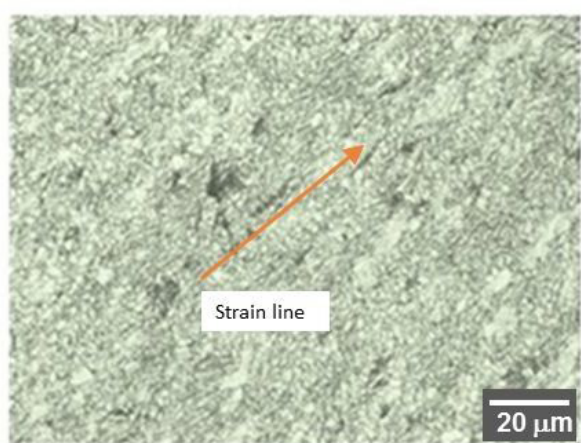

(b)

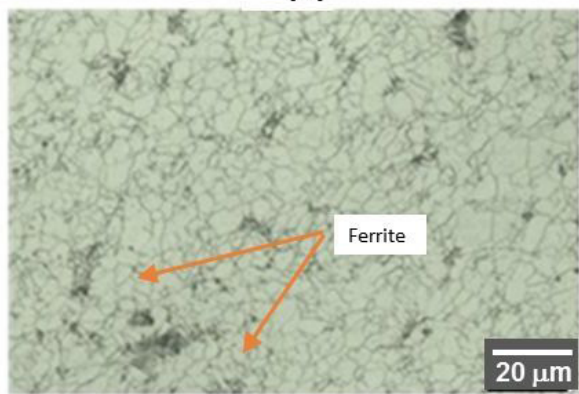

(d)

Figure 10. Low carbon steel at $800^{\circ} \mathrm{C}, 200 \mathrm{X}$ (a) Alone quenched, (b) strain rate $0.1 \mathrm{~s}^{-1}$, (c) $0.01 \mathrm{~s}^{-1}$ and (d) $0.001 \mathrm{~s}^{-1}$.
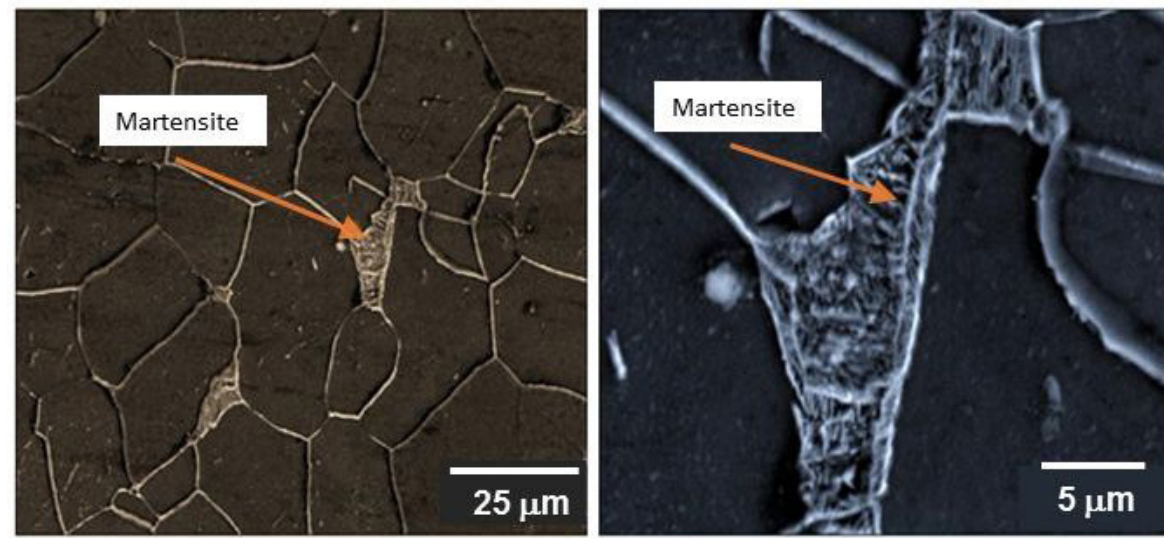

Figure 11. Microstructure of 1008 steel deformed at $800^{\circ} \mathrm{C}, 1000 \mathrm{X}$ and $4000 \mathrm{X}$, strain rate of $10^{-1} \mathrm{~s}^{-1}$. Martensite in a ferritic matrix.
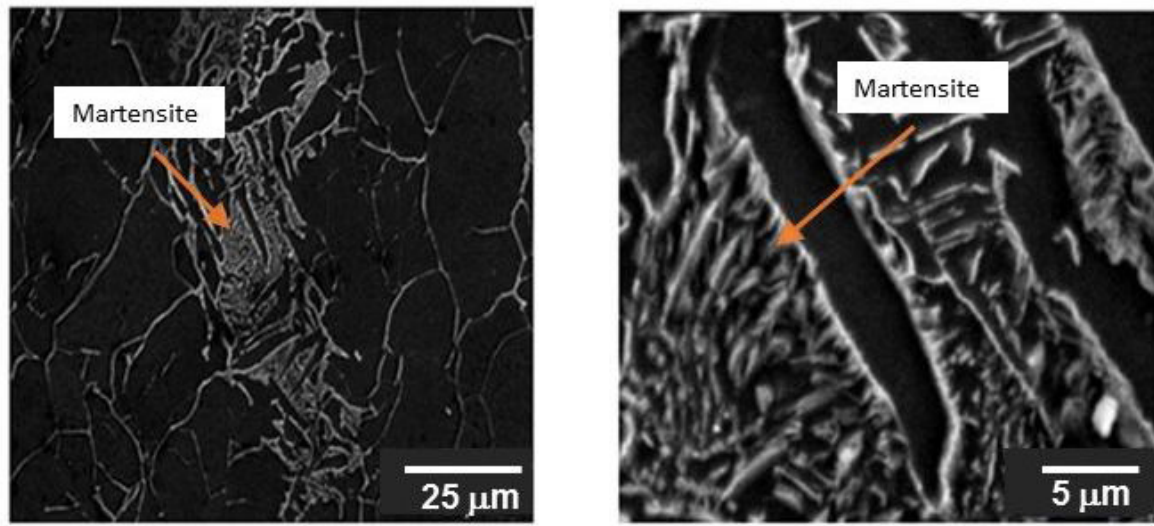

Figure 12. Microstructure of 1008 steel deformed at $800^{\circ} \mathrm{C}, 1000 \mathrm{X}$ and $4000 \mathrm{X}$, strain rate $10^{-2} \mathrm{~s}^{-1}$. Martensite in a ferritic matrix. 

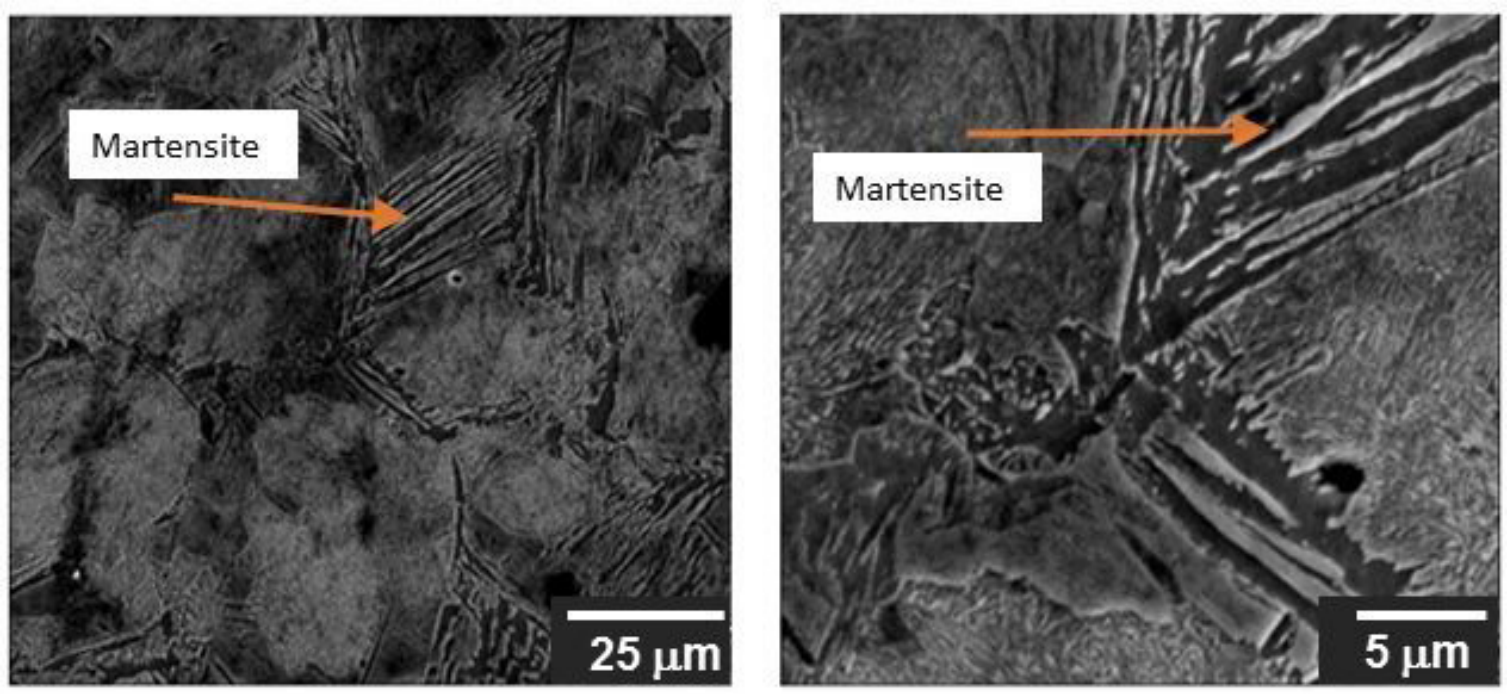

Figure 13. Microstructure of 1035 steel deformed at $785^{\circ} \mathrm{C}, 1000 \mathrm{X}$ and $4000 \mathrm{X}$, strain rate $10^{-1} \mathrm{~s}^{-1}$. Martensite in a ferritic matrix.
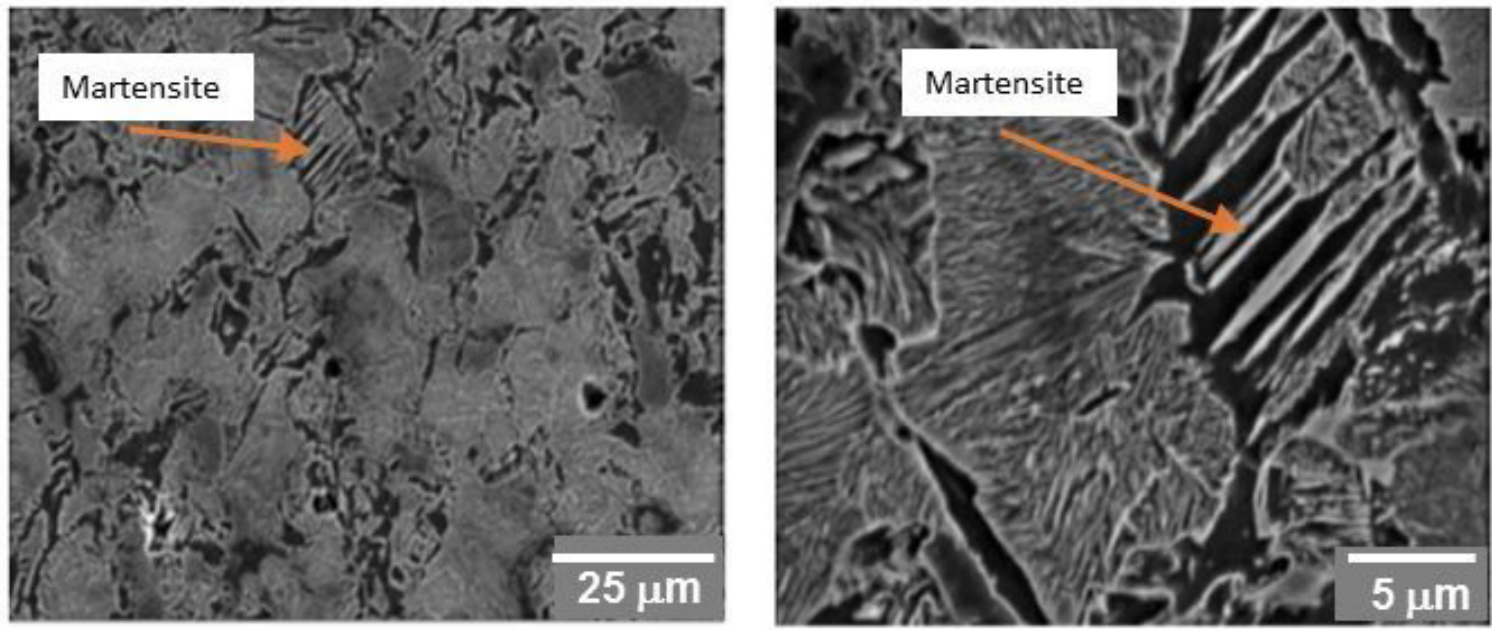

Figure 14. Microstructure of 1035 steel deformed at $785^{\circ} \mathrm{C}, 1000 \mathrm{X}$ and $4000 \mathrm{X}$, strain rate $10^{-2} \mathrm{~s}^{-1}$.
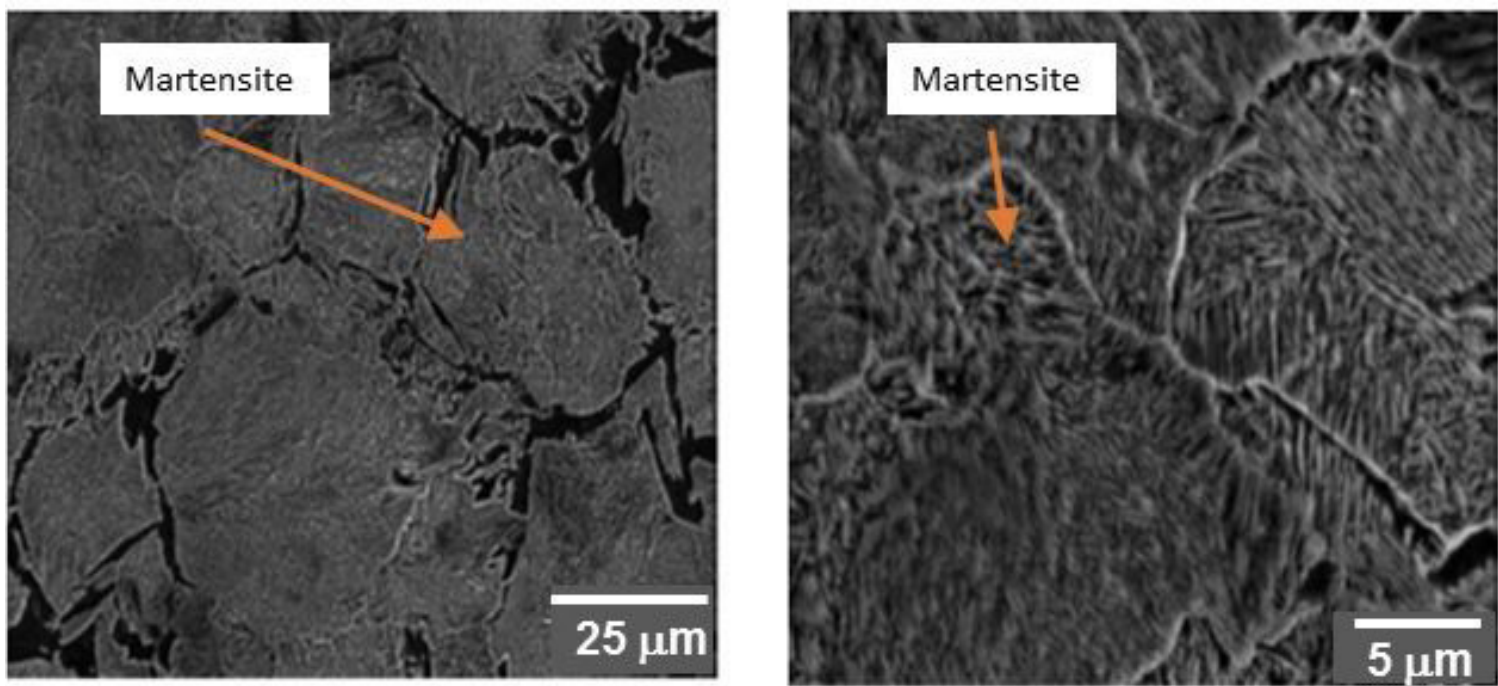

Figure 15. Microstructure of 1035 steel deformed at $785^{\circ} \mathrm{C}, 1000 \mathrm{X}$ and $4000 \mathrm{X}$, strain rate $10^{-3} \mathrm{~s}^{-1}$. 

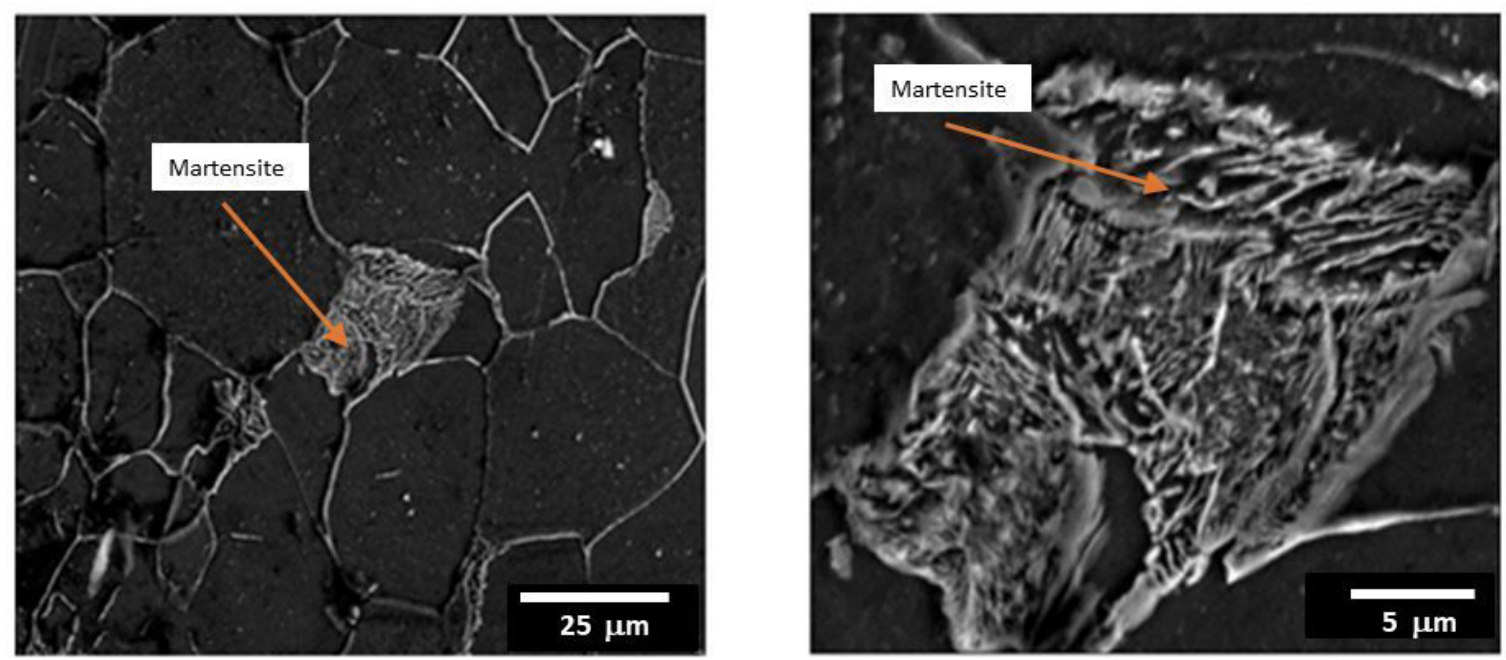

Figure 16. Microstructure of 1008 steel deformed at $800^{\circ} \mathrm{C}, 1000 \mathrm{X}$ and $4000 \mathrm{X}$, strain rate $10^{-2} \mathrm{~s}^{-1}$.

\section{Conclusions}

- Ageneric Constitutive Modeling of hot deformation in the intercritical zone for alloys Fe-C-Mn-Si is proposed, where all the parameters are only a function of the strain rate and the alloy's chemical composition.

- The model was validated by hot compression tests of steels $\mathbf{1 0 0 8}$ and $\mathbf{1 0 3 5}$ at different temperatures and under different strain rates in the intercritical zone.

- Experimental stress-strain curves were adjusted to a theoretical model based on the law of mixtures of deformation for austenite and ferrite.

- The true stress-strain curves $\sigma$ - $\varepsilon$ resulting from the tests of isothermal uniaxial compression followed the expected behavior with the variation of the temperature and true strain rate. That is, an increase in temperature or a decrease in the strain rate was found to lead to a decrease in the yield stress and vice versa.

- A good agreement between the experimental and predicted results was obtained. The iso-deformation hypothesis is fulfilled in both phases.

The proposed generic constitutive modeling is suitable for application in the constitutive modeling of thermomechanical forming operations of $\mathrm{Fe}-\mathrm{C}-\mathrm{Mn}$-Si metal alloys in the intercritical temperature range.

\section{Acknowledgement}

The authors wish to thank the Institutions CONACyT, National Polytechnic Institute and Polytechnic University of Catalonia for their assistance to Process Metallurgy Group at ESIQIE-Metallurgy and Materials Department.

\section{References}

1. Suárez L, Rodríguez-Calvillo P, Cabrera JM, Martínez-Romay A, Majuelos Mallorquín D, Coma A. Hot working analysis of a $\mathrm{CuZn} 40 \mathrm{~Pb} 2$ brass on the monophasic $(\beta)$ and intercritical $(\alpha+\gamma)$ regions. Mat Sci Eng A. 2015;627:42-50. http://dx.doi. org/10.1016/j.msea.2014.12.093.

2. Varela CG. Efecto de los contenidos de C, Si y Mn en el comportamiento a fluencia en caliente de aceros de construcción al carbono. Aplicación a la obtención de grano ultrafino en productos largos laminados [thesis]. Barcelona: Universitat Politécnica de Cataluña; 2012

3. Ghosh S, Somani MC, Setman D, Mula S. Hot deformation characteristic and strain dependent constitutive flow stress modelling of $\mathrm{Ti}+\mathrm{Nb}$ stabilized interstitial free steel. Met Mater Int. 2021;27:2481-98. http://dx.doi.org/10.1007/s12540-02000827-1.

4. Ghosh S, Kömi J, Mula S. Flow stress characteristics and design of innovative 3-steps multiphase control thermomechanical processing to produce ultrafine grained bulk steels. Mater Des. 2019;186:108297. http://dx.doi.org/10.1016/j.matdes.2019.108297.

5. Rodríguez-Calvillo P, Boulaajaj A, Perez-Sine M, Schneider J, Cabrera JM. On the hot working of FeSi ferritic steels. Mater Sci Eng A. 2014;A606:127-38. http://dx.doi.org/10.1016/j. msea.2014.03.073.

6. Patnamsetty M, Somani MC, Ghosh S, Ahmad S, Peura P. Processing map for controlling microstructure and unraveling various deformation mechanisms during hot working of $\mathrm{CoCrFeMnNi}$ high entropy alloy. Mater Sci Eng A. 2020;793:139840. http:// dx.doi.org/10.1016/ j.msea.2020.13984.

7. Ghosh S, Somani MC, Setman D, Mula S. Elucidation of deformation mechanisms and construction of processing maps for a Ti+Nb stabilized IF steel. Mater Sci Eng A. 2020;790:139648. http://dx.doi.org/10.1016/j.msea.2020.139648.

8. Mintz B, Banerjee JR, Banks KM. Regression equation for $\mathrm{Ar}_{3}$ temperature for coarse grained as cast steels. Ironmak Steelmak. 2011;38(3):197-203. http://dx.doi.org/10.1179/030 $192310 X 12827375731429$.

9. Mintz B, Cowley A. Deformation induced ferrite and its influence on the elevated temperature tensile flow stress-elongation curves of plain C-Mn and $\mathrm{Nb}$ containing steels. Mater Sci Technol. 2006;22(3):279-92. http://dx.doi.org/10.1179/174328406X91177.

10. Dieter GE. Mechanical metallurgy. London: McGraw-Hill Book Company; 1988.

11. Mohapatra G, Sommer F, Mittemeijer EJ. Calibration of a quenching and deformation differential dilatometer upon heating and cooling: thermal expansion of $\mathrm{Fe}$ and $\mathrm{Fe}-\mathrm{Ni}$ 
alloys. Thermochim Acta. 2007;453(1):31-41. http://dx.doi. org/10.1016/j.tca.2006.11.007.

12. Prasad Y, Rao KP, Sasidhara S, editors. Hot working guide-a compendium of processing maps. USA: ASM Int.; 2015.

13. Sellars CM, Whiteman JA. Recrystallization and grain growth in hot rolling. Met Sci. 1979;13:187-94.

14. Cowley A, Abushosha R, Mintz B. Influence of $\mathrm{Ar}_{3}$ and $\mathrm{Ae}_{3}$ temperatures on hot ductility of steels. Mater Sci Technol. 1998;14(11):1145-53. http://dx.doi.org/10.1179/mst.1998.14.11.1145.

15. Zener C, Hollomon JH, MacGregor CW, Fisher JC. A velocitymodified temperature for the plastic flow of metals. J Appl Mech-Trans of the ASME. 1947;14(1):A70-1.

16. Bergstrom Y, Aronsson B. The application of a dislocation model to the strain and temperature dependence of the strain hardening exponent $\mathrm{n}$ in the Ludwik-Hollomon relation between stress and strain in mild steels. Metall Trans. 1972;3(7):1951-7.

17. Sakai T, Jonas JJ. Dynamic recrystallization: mechanical and microstructural considerations. Acta Metall. 1984;32(2):189209. http://dx.doi.org/10.1016/0001-6160(84)90049-X.

18. Estrin Y, Mecking H. A unified phenomenological description of work hardening, and creep based on one-parameter model. Acta Metall. 1984;32(1):57-70. http://dx.doi.org/10.1016/00016160(84)90202-5.

19. McQueen HJ, Yue S, Ryan ND, Fry E. Hot working characteristics of steels in austenitic state. J Mater Process Technol. 1995;53(12):293-310. http://dx.doi.org/10.1016/0924-0136(95)01987-P.

20. Roberts W, Krauss G, editors. Deformation, processing and structure. USA: ASM; 1982.

21. Kocks UF. Laws for work-hardening and low-temperature creep. J Eng Mater Technol. 1976;8(1):76-85.

22. Bergström Y. A dislocation model for the stress-strain behaviour of polycrystalline $\alpha$-Fe with special emphasis on the variation of the densities of mobile and immobile dislocations. Mater Sci Eng. 1970;5(4):193-200.

23. Bergström Y, Aronsson B. The application of a dislocation model to the strain and temperature dependence of the strain hardening exponent $\mathrm{n}$ in the Ludwik-Hollomon relation between stress and strain in mild steels. Metall Trans. 1972;3:1951-7.

24. Hartley P, Sturgess CEN, Rowe GW. Prediction of deformation and homogeneity in rim disc forging. J Mech Work Tech. 1980;4(2):145-54.

25. Li G, Kobayashi S. Rigid-plastic finite-element analysis of plane strain rolling. J Eng Ind. 1982;104:55-64.
26. Ghosh AK. A physically-based constitutive modeling for metal deformation. Acta Metall. 1980;28(11):1443-65. http://dx.doi. org/10.1016/0001-6160(80)90046-2.

27. Rao KP, Hawbolt EB. Development of constitutive relationships using compression testing of a medium carbon steel. J Eng Met Tech. 1992;114:116-23. http://dx.doi.org/10.1115/1.2904131.

28. Hartley CS, Srinivasan R. Constitutive equations for large plastic deformation of metals. J Eng Mater Technol. 1983;105:162-7. http://dx.doi.org/10.1115/1.3225636.

29. Sellars CM. Tegart WJ. Hot workability. Int Met Reviews. 1972;17:1-24.

30. Sellars CM, Tegart WJ. Relation between strength and structure in hot deformation. Mem Sci Rev Metall. 1966;63:731-46.

31. Jonas JJ, Sellars CM, Tegart WJ. Strength and structure under hot working conditions. Metall. Rev. 1969;14(1):1-24.

32. Dadras P. Flow stress equations for the type 304 stainless and AISI 1055 steels. J Eng Mater Technol. 1985;107:97-100. http:// dx.doi.org/10.1115/1.3225798.

33. Charpentier PL, Stone BC, Ernst SC, Thomas JF Jr. Characterization, and modeling of the high temperature flow behavior of Aluminum alloy 2024. Metall Trans. 1986;17A:2227-37. http://dx.doi. org/10.1007/BF02645920.

34. Saito Y, Enami T, Tanaka T. The mathematical model of hot deformation resistance with reference to microstructural changes during rolling in plate mill. Trans ISIJ. 1985;25:1146-55.

35. Klepaczko JR. A practical stress - strain - strain-rate temperature constitutive relation of the power form. J Mech Work Tech. 1987; 15:143-65.

36. Ouchi C, Okita T, Ichihara T, Ueno Y. Hot deformation strength of austenite during controlled tolling in a plate mill. Trans ISIJ. 1980;20:833-41.

37. Hatta N, Kokado J, Kikuchi S, Takuda H. Modelling of flow stress of plain carbon steel at elevated temperatures. Steel Res. 1985;56(11):575-82.

38. Baragar DL. The high temperature and high strain-rate behavior of a plain carbon and an HSLA steel. J Mech Work Tech. 1987; 14:295-307.

39. Zhao Y, Li X, Zhang W, Devesh R, Misra K, Liu Z. Strain partitioning and softening mechanisms of $\delta / \gamma$ in lean duplex stainless steels during hot deformation. Steel Res Int. 2019;91(1):1900212. http://dx.doi.org/10.1002/srin.201900212.

40. Momeni A, Kazemi S, Bahrani A. Hot deformation behavior of microstructural constituents in a duplex stainless steel during hightemperature straining. Int J Miner Metall Mater. 2013;20(10):95360. http://dx.doi.org/10.1007/s12613-013-0820-6. 


\section{Supplementary material}

The following online material is available for this article:

Appendix A - List of Symbols. 